\title{
Transferência de Valor e Desenvolvimento Desigual: uma Análise Comparada
}

\section{Value Transfer and Uneven Development: a Comparative Analysis}

Lucas Rodrigues*

Resumo: Este artigo tem o objetivo de apresentar o tratamento acerca da transferência de valor e do desenvolvimento desigual a partir da teoria clássicomarxista da concorrência e das vantagens absolutas. O modo como essa teoria aborda o problema se afasta daquelas que percebem uma relação direta entre transferência de valor entre nações e subdesenvolvimento. Entende-se o desenvolvimento desigual e a transferência de valor como intrínsecos ao processo de acumulação de capital e estabelece-se que a análise do problema deve ser feita primeiramente ao nível dos diferentes capitais, e não das diferentes nações.

Palavras-chave: Transferência de valor. Desenvolvimento desigual. Concorrência.

Abstract: This article aims to provide a treatment on the value transfer and uneven development from the classic Marxist theory of competition and absolute advantages. The way this theory addresses the problem maintain an important difference from those who perceive a direct relationship in value transfer between nations and underdevelopment. The understanding proposed here sees the uneven development and the transfer of value as intrinsic to the capital accumulation process and it establishes that the problem analysis must be done first at the level of different capitals and not of the different nations.

Keywords: Value transfer. Uneven development. Competition.

JEL Classification: B51; F1; F31.

Doutorando em Desenvolvimento Econômico pelo Programa de Pós-Graduação em Economia da Universidade Federal do Rio Grande do Sul (PPGE-UFRGS). E-mail: lucas_r1@hotmail.com 


\section{Introdução}

A questão da transferência de valor entre nações tem apresentado um papel central no pensamento crítico latino-americano ${ }^{1}$ e nas várias tentativas de se entender a situação e manutenção do subdesenvolvimento, em especial nas correntes teóricas de vertente marxista. Em linhas gerais, tais teorias defendem que a relação de troca que se estabelece entre as regiões atrasadas e avançadas e o modo como são formados os preços das mercadorias produzidas em cada um desses locais dão lugar a uma constante transferência de parte do valor criado nas regiões atrasadas para as avançadas. Essas transferências estariam na base das restrições ao investimento na periferia, da impossibilidade de internalização de certos setores e na limitação ao desenvolvimento de um mercado interno robusto. Como causas fundamentais dessa relação, encontram-se: o menor desenvolvimento das forças produtivas na periferia; os menores salários nessas regiões e, consequentemente, o maior grau de exploração de sua força de trabalho; as relações de monopólios que os países centrais impõem aos países periféricos; e, ainda, fatores extraeconômicos, como a coerção e a pilhagem. Algumas importantes implicações decorrem dessa forma de compreensão do subdesenvolvimento, entre elas a centralidade da exploração entre nações e o caráter preferencialmente intersetorial da transferência de valor.

Um segundo grupo de autores (SHAIKH, 1980a, 1980b, 1991b; ASTARITA, 2004; CARCHEDI, 1991; GUERRERO, 1995, 1996), no entanto, partindo da teoria clássico-marxista das vantagens absolutas nas trocas internacionais e da teoria clássico-marxista da concorrência, ${ }^{2}$ propõe que a análise das transferências de valor deve ser feita primeiramente no nível dos diferentes capitais, e não das diferentes nações. Como base para tal defesa está o resgate dos vários mecanismos de transferência de valor via preços tratados por Marx. O desenvolvimento desigual também deve ser compreendido como uma característica inerente ao processo de acumulação de capital, que se expressa primeiramente em um desenvolvimento desigual entre os diferentes capitais e setores que compõem o capital social total. Uma implicação de tal abordagem é de que é o processo de concorrência entre

1 Para uma exposição sucinta das principais correntes e autores do pensamento crítico latino-americano, ver Palma (2009).

2 Seguindo os pressupostos de tal teoria, considera-se que a concorrência não reflete uma organização de mercado, mas sim a expressão externa do processo de valorização de capital. Nesse sentido, assume duas formas, uma intrassetorial e outra intersetorial. A primeira forma ocorre quando o processo concorrencial aparece como a busca constante por se produzir com menores custos e tem como resultado a formação dos valores sociais e um processo de diferenciação dos lucros das empresas de um mesmo setor. Já a segunda forma se dá quando esse processo se apresenta no fluxo contínuo de capital em direção aos setores de maior lucratividade, tendo como resultado uma tendência à equalização das taxas de lucro entre setores e a formação dos preços de produção. Para uma abordagem mais detalhada sobre o tema, ver Shaikh (1979, 1980a, 1991a,), Maldonado Filho (1990), Baskoy (2002), Semmler (1982). 
capitais que desencadeia o fenômeno do desenvolvimento desigual, e não o processo de troca.

O presente artigo tem como objetivo explorar o desenvolvimento teórico dado por esse segundo grupo de autores acerca das transferências de valor e do processo de desenvolvimento desigual. Iniciando a exposição são apresentados alguns pontos principais para Emmanuel (1976), Amin (1976, 2010) e Marini (1973), autores considerados expoentes do primeiro grupo teórico citado, que percebem uma relação direta entre transferência de valor e subdesenvolvimento. Não se busca, no entanto, um aprofundamento sistemático de suas teorias, mas apenas um levantamento dos pontos principais de divergência entre eles e a abordagem aqui exposta. A escolha por tais autores se justifica pela importância de seus escritos para o tema em questão e por tratarem dos principais elementos que caracterizam essa corrente de pensamento: diferenciais de salários, ação dos monopólios e relação centro-periferia. Não se pretende, no entanto, tomá-los como uma corrente de pensamento completa. Na seção seguinte são apresentados os vários mecanismos de transferência de valor via preços tratados pela teoria clássico-marxista das vantagens absolutas e as implicações de tal abordagem para a questão da transferência de valor entre nações. A última seção propõe uma forma de se compreender o desenvolvimento desigual a partir, preferencialmente, do funcionamento da concorrência em escala global e não do processo de troca entre nações de diferentes graus de desenvolvimento.

\section{Trocas Desiguais e Subdesenvolvimento}

Desde Prebisch, com seu estudo acerca da deterioração dos termos de troca, o comércio internacional entre periferia e centro foi identificado como o grande fator de manutenção do subdesenvolvimento. A partir de tal estudo, e dentro do campo marxista, inúmeros autores passaram a analisar o fenômeno das trocas internacionais e apontar que se caracteriza por uma constante transferência de valor dos países atrasados para os países avançados. Esse processo teria como resultado a diminuição na capacidade de investimento nessas economias atrasadas, ao mesmo tempo que alimentaria o crescimento econômico dos países centrais, gerando, de acordo com Frank (1970), um verdadeiro ciclo vicioso de "desenvolvimento do subdesenvolvimento". Segundo Brewer (1990, p. 164), ao referir-se ao trabalho desse autor:

The "development of underdevelopment" occurs because the world capitalist system is characterized by a metropolis-satellite structure. The metropolis exploits the satellite, surplus is concentrated in the metropolis, and the satellite is cut off from potential investment funds, so its growth is slowed down. More important, the satellite is reduced to a state of depen- 
dence which creates a local ruling class with an interest in perpetuating underdevelopment, a "lumpenbourgeoisie" which follows a "policy of underdevelopment” (BREWER, 1990, p. 164).

Apesar de divergências em várias frentes, percebe-se que os autores que seguem tal linha de análise afirmam que existem diferenças no modo como se estabelecem os preços das mercadorias exportáveis nos países atrasados e nos países avançados. Suas distintas características, como diferenças salariais, de produtividade, ou mesmo, fatores extraeconômicos determinam que os preços se estabeleçam de forma a proporcionar uma extração de mais-valia por parte dos países centrais. Na sequência, aborda-se mais detalhadamente como se dá tal processo de transferência de valor nas obras de Emmanuel, Amin e Marini, autores de fundamental importância no debate sobre o tema.

Ao tratar das trocas desiguais, Emmanuel inicia seu trabalho apontando para o que identifica ser o principal suposto da teoria das vantagens comparativas de Ricardo, a imobilidade do capital. Segundo Emmanuel, a superação de tal imobilidade gera a possibilidade do capital explorar as mais diversas áreas, se aproveitando dos benefícios de cada uma delas. Nesse sentido, considera que os diferencias de custos de implantação de uma planta produtiva tendem a igualar-se nas distintas regiões, sendo que os diferenciais de salários aparecem como o fator central de atração dos capitais. São esses diferenciais, aliados a uma tendência global de equalização das taxas de lucro, que estão na base da extração da mais-valia produzida na periferia por parte dos países avançados. De acordo com o autor, não são as características específicas dos produtos produzidos nos países atrasados - produtos primários com baixa elasticidade-preço - que determinam o comportamento de seus preços e a deterioração dos termos de troca, mas sim o fato de essas mercadorias serem produzidas em países de baixos salários enquanto as dos países centrais são produzidas com altos salários.

Num primeiro momento, os países centrais, dado seus altos salários e alta composição orgânica do capital, apresentam baixas taxas de lucro. Nos países periféricos, por outro lado, o baixo desenvolvimento das forças produtivas e os baixos salários lhes conferem uma maior produção de mais-valia e uma maior taxa de lucro. ${ }^{3} \mathrm{O}$ capital se move em direção a essas regiões em busca dessa maior lucratividade, iniciando uma tendência mundial de equalização das taxas de lucro. Caso o capital fosse imóvel internacionalmente, as altas taxas de lucro na periferia levariam a um aumento nos preços de produção das mercadorias desses países, e, des-

3 Para Emmanuel (1976), o salário aparece como variável independente do modelo. Seguindo Marx, ele trata dos elementos históricos e morais na determinação dos salários, mostrando que esses elementos tendem a convergir dentro de um mesmo país, porém não guardam relação direta na esfera internacional. Dessa forma, afirma: "[...] os salários não são os efeitos, mas a causa dos preços, enquanto que os lucros são determinados pela taxa geral média” (EMMANUEL, 1976, p. 145). 
sa forma, não haveria trocas desiguais. No entanto, como os capitais estrangeiros migram de seus países de origem, conseguem, a partir da exploração dos países atrasados, contrabalancear a queda em suas taxas de lucro e garantir altos salários para sua classe trabalhadora. Aliado a isso, esses capitais estrangeiros, dada a menor taxa de lucro vigente em seus países de origem, ao migrarem para os países atrasados se sujeitam a uma remuneração menor de seus capitais do que aquela até então auferida pelos capitalistas locais. Tal fato contribui para que os capitais internacionais se sobreponham aos capitais dessas nações atrasadas. Por tal motivo, apesar da possibilidade de maiores taxas de lucro nesses países, o que poderia se traduzir em uma maior capacidade de investimento na periferia e, assim, uma diminuição das brechas entre as nações, a mobilidade internacional do capital faz com que o processo de desenvolvimento seja marcadamente desigual. Diferenças salariais e perequação das taxas de lucro estão, portanto, na base das trocas desiguais. Segundo Emmanuel (1976, p. 122),

Para além de toda e qualquer alteração de preços resultante de uma concorrência imperfeita no mercado das mercadorias, a troca desigual é a relação dos preços de equilíbrio que se estabelece em virtude da perequação dos lucros entre regiões com taxas de mais-valia "institucionalmente" diferentes - significando o termo institucionalmente que essas taxas escapam, seja por que razão for, à perequação concorrencial no mercado dos fatores e são independentes dos preços relativos (EMMANUEL, 1976, p. 122).

Uma grande contribuição de tal autor, nesses termos, é tratar o funcionamento dos mecanismos concorrenciais na esfera internacional da mesma maneira que na esfera nacional. Nesse sentido, os preços de produção tendem a formar-se mundialmente, com a particularidade de uma não equalização dos salários. O resultado da formação de preços de produção com taxas desiguais de salários, segundo o autor, é que, apesar de as mercadorias dos países periféricos conterem uma maior quantidade total de trabalho vivo, a parte variável do capital total adiantado é menor, de forma que essa quantidade maior de trabalho vivo se expressa em um preço de produção menor, fazendo com que, nas trocas internacionais, a periferia troque mais trabalho por menos trabalho. O exemplo a seguir, retirado de Howard e King (1992, p. 190-191), ilustra esse movimento.

Considerando-se dois países $A$ e $B, A$ produz 30 carros utilizando 720 dias de trabalho direto e indireto, expressos em $\$ 600,00$, e $B$ produz 30 toneladas de chá com 480 dias de trabalho, também direito e indireto, expressos em $\$ 300,00$. Ambos os capitais apresentam a mesma composição orgânica, igual a 4, porém os salários são menores em $B$, de forma que a mais-valia nesse país é de $300 \%$, enquanto, em A, é de 100\%. A Tabela 1 ilustra esse cenário: 
Tabela 1 - Preços de produção sem mobilidade internacional de capital

\begin{tabular}{c|c|c|c|c|c}
\hline País & $\begin{array}{c}\text { Capital } \\
\text { constante (\$) }\end{array}$ & $\begin{array}{c}\text { Capital } \\
\text { variável (\$) }\end{array}$ & $\begin{array}{c}\text { Mais- } \\
\text { valia (\$) }\end{array}$ & $\begin{array}{c}\text { Valor } \\
\text { total (\$) }\end{array}$ & $\begin{array}{c}\text { Valor por } \\
\text { unidade de } \\
\text { produto (\$) }\end{array}$ \\
\hline $\mathrm{A}$ & 480 & 120 & 120 & 720 & $720 / 30=24$ \\
\hline $\mathrm{B}$ & 240 & 60 & 180 & 480 & $480 / 30=16$ \\
\hline
\end{tabular}

Fonte: Elaboração própria a partir de Howard e King (1992).

Em situação de imobilidade do capital na esfera internacional, o país A apresentaria uma taxa de lucro igual a 20\% (120/600), enquanto que a taxa de lucro para o país B seria de $60 \%$ (180/300). No entanto, dado que o capital se move dos locais de menor lucratividade para os de maior, a taxa de lucro tende a se igualar entre esses dois locais. A nova taxa de lucro que se estabelece para ambos é de 33,33\% (300/900), dada pela divisão entre a mais-valia criada e o capital total adiantado, em ambos os países. Com a equalização das taxas de lucro, se formam os preços de produção, sendo que, para os carros produzidos em $A$, são iguais a $\$ 800,00$ e, para o chá produzido no país $B$, são iguais a $\$ 400,00$, como na Tabela 2:

Tabela 2 - Preços de produção com mobilidade internacional de capital

\begin{tabular}{c|c|c|c|c}
\hline País & $\begin{array}{c}\text { Preços } \\
\text { de custo } \\
\text { (c + v) }\end{array}$ & $\begin{array}{c}\text { Lucros } \\
\mathbf{r}(\mathbf{c}+\mathbf{v})\end{array}$ & $\begin{array}{c}\text { Preços de } \\
\text { produção } \\
(\mathbf{1}+\mathbf{r})(\mathbf{c}+\mathbf{v})\end{array}$ & $\begin{array}{c}\text { Preços por unidade } \\
\text { de produto }\end{array}$ \\
\hline A & 600 & 200 & 800 & $800 / 30=80 / 3$ \\
\hline B & 300 & 100 & 400 & $400 / 30=40 / 3$ \\
\hline
\end{tabular}

Fonte: Elaboração própria a partir de Howard e King (1992).

De acordo com o exemplo dos autores, o país $A$ importa 6 toneladas de chá a um preços de 6 × 40/3 = $\$ 80,00$, de forma que o país $B$, para não incorrer em déficits, poderá importar 3 carros, também a 3 x 80/3 =\$80,00. Ocorre, no entanto, que o valor trabalho das importações do país $B$ (carros) é igual a $3 \times 24=\$ 72,00$, enquanto o valor trabalho de suas exportações (chá) é de 6 x $16=\$ 96,00$. Estabelece-se, dessa forma, um intercâmbio desigual em prejuízo do país $B$, de forma que "[...] of the 60 days of surplus labour performed in the poor country only 36 remain there, the other 24 being transferred to the rich country in the course of trade [...]" (HOWARD; KING, 1992, p. 191).

Para Emmanuel, um dos resultados das trocas desiguais é o rompimento da solidariedade da classe trabalhadora a nível mundial. Como essa transferência de valor se opera dos países atrasados para os centrais, favorece que parte seja apropriada pela classe trabalhadora das nações avançadas, que tenderiam a abandonar a luta em favor de uma nova forma de organização social. Essa classe, pelo 
contrário, concentraria seus esforços na busca pela manutenção e aumento de seus salários, o que alimentaria a brecha salarial entre os países e aceleraria ainda mais as trocas desiguais (EMMANUEL, 1976, p. 247). Uma equiparação dos salários entre os dois grupos de países seria o único caminho para o fim desse tipo de intercâmbio. Dada a dificuldade para que isso venha a ocorrer, Emmanuel aponta para saídas que amenizem as trocas desiguais e façam com que a mais-valia permaneça nos países atrasados. Uma saída seria uma maior taxação dos produtos exportáveis, porém poderia gerar retaliações que reverteriam os benefícios. Uma segunda saída seria a diversificação produtiva, principalmente na forma de substituição de importações, de modo a fazer com que as economias atrasadas passassem a depender menos do comércio internacional (EMMANUEL, 1976, p. 349).

Amin (1976, 2010), por sua vez, parte da exposição de Emmanuel e procura adicionar certos apontamentos à questão das trocas desiguais. Segundo ele, esse é um tema posterior aos escritos de Marx, dado que se torna relevante apenas após 1880, quando o capitalismo entra em sua fase monopolista. Essa mudança qualitativa no funcionamento do modo de produção capitalista teria feito com que o processo visto até esse momento, no qual os ganhos de produtividade se refletiam em queda nos preços, tomasse um rumo contrário. Dessa forma, com o estabelecimento dos monopólios, o que se assiste é que o progresso técnico se traduz em um movimento de alta dos preços e, principalmente, das rendas. Segundo ele:

[a formação dos monopólios] É o que explica que ao longo de todo século XIX o progresso técnico se tenha traduzido pela baixa dos preços enquanto que depois de 1880-1890 se assiste à alta contínua dos preços e à alta mais rápida das rendas (salários e lucros) os quais traduzem o progresso. O monopólio torna a alta dos salários possíveis, pois que a concorrência daí em diante não se baseia mais nos preços; assim se explica que a deterioração dos termos de troca tenha aparecido para os países subdesenvolvidos com o nascimento dos monopólios, o imperialismo e a “aristocracia operária” (AMIN, 1976, p. 142).

Amin (1976) concorda, dessa forma, com Emmanuel ao apontar que o problema da deterioração dos termos de troca não está dado pelos tipos distintos de mercadorias que se produzem nos países centrais e periféricos, mas sim pelas estruturas dos capitais, que são distintas em cada região. Nos países centrais, o modo de produção capitalista tenderia a generalizar-se mais rapidamente, absorvendo as relações pré-capitalistas, gerando um desenvolvimento mais acelerado. $\mathrm{Na}$ periferia, por outro lado, o desenvolvimento seria bloqueado pelos capitais mais avançados do centro, o que se refletiria em uma permanência de relações pré-capitalistas (BREWER, 1990, p. 199). Dessa forma, nos países atrasados, os capitais ainda estariam sujeitos ao processo concorrencial, ou mesmo submetidos a outras relações de produção, de modo que o comportamento de seus preços apre- 
sentaria tendência à queda. Nos países centrais, graças à estrutura monopolista, os ganhos de produtividade não seriam transmitidos aos preços das mercadorias. $\mathrm{O}$ resultado das trocas desiguais, assim como para Emmanuel, se daria na forma de aumentos das rendas no centro, gerando ganhos mesmo para a classe trabalhadora desses países.

De acordo com Amin, a formação dos monopólios não apenas favorece as trocas desiguais, mas também permite que o capital se expanda mundialmente. Nesse sentido, a exportação de capitais e a sua instalação na periferia levam a um processo mundial de equalização das taxas de lucro, "[...] a qual constitui a essência da troca desigual” (AMIN, 1976, p. 152). Essa exportação de capitais não modifica, no entanto, o papel da periferia na transferência de valor. Mesmo que esses capitais resultem em uma diversificação produtiva, essa continua cumprindo seu papel subsidiário de fornecer aquelas mercadorias necessárias aos países centrais. Segundo Amin, a própria exportação de capitais é um meio de "[...] impor à periferia essas produções necessárias ao centro [...]” (AMIN, 1976, p. 152). Dessa forma, os capitais desses países centrais se veem duplamente beneficiados: em primeiro lugar, porque podem apropriar-se das maiores taxas de lucro, típicas dos países atrasados; ${ }^{4}$ em segundo lugar, pois possuem tanto as matérias-primas barateadas e os bens semiacabados que necessitam, quanto acesso a bens de consumo mais baratos para a classe trabalhadora.

As diferenças no processo de desenvolvimento do modo de produção capitalista nessas diferentes regiões geram ainda uma segunda distorção. Enquanto, nos países centrais, o desenvolvimento é caracteristicamente autocentrado, ou seja, governado por sua própria dinâmica interna, nas economias periféricas ele se dá basicamente voltado para fora. A relação entre os departamentos produtores de meios de produção e os produtores de meios de consumo se estabelece de forma plena nos países desenvolvidos, enquanto que, nos atrasados, essa relação é débil, tornando esses países dependentes do progresso técnico do centro. Esses fatores, que se traduzem em uma falta de estímulos internos para o desenvolvimento econômico periférico, fazem com que os salários nos países atrasados apareçam apenas como custos e não como componentes de demanda (AMIN, 1976, p. 163). Aliado a isso, Amin (1976) argumenta que, enquanto nos países centrais a maior

$4 \quad$ Essas maiores taxas de lucro na periferia apenas permaneceriam em um primeiro momento, sendo que o efeito dos fluxos de capitais dos países centrais para essas regiões seria uma tendência mundial de equalização dessas taxas. A absorção das atividades realizadas nos países atrasados ou o desenvolvimento de novas atividades, inauguradas pelos capitais internacionais, teriam, para Amin, o efeito final de elevar a taxa de lucro média global. No entanto, segundo o autor, a existência dos monopólios distorce esse processo de equalização, fazendo surgir a tendência à formação de ao menos duas taxas de lucro: uma para o setor monopolista e outra para o setor sujeito à concorrência (AMIN, 1976, p. 56). Nesse sentido, dois fatores contribuiriam para as trocas desiguais: por um lado, a equalização internacional das taxas de lucro em situação de salários distintos entre os países; por outro lado, as trocas entre os setores concorrenciais e monopolistas. 
parte dos rendimentos da classe dominante são lucros, nos países periféricos esses rendimentos aparecem principalmente na forma de rendas fundiárias. Esse fator, aliado à atrofia dos setores produtores de bens de produção nas economias atrasadas, faz com que, diferentemente do que ocorre nos países centrais, o aumento dos ganhos da classe dominante não se traduza em investimentos produtivos, mas assim em uma absorção maior de força de trabalho. ${ }^{5}$ Os salários tenderiam, assim, a apresentar dinâmicas distintas e persistentes entre os dois grupos de países, favorecendo que as trocas desiguais se efetuem mesmo com diversificação produtiva.

Uma terceira linha de argumentação, que identifica as trocas desiguais como a característica fundamental da relação comercial entre países avançados e atrasados, é apresentada pelos autores da chamada teoria marxista da dependência. Segundo eles, o mundo capitalista é marcado por uma estrutura centro-periferia, na qual os países centrais exploram os países atrasados e se apropriam da mais-valia gerada nestes. Estabelecem-se entre esses dois grupos de países uma relação de monopólio em favor dos primeiros. Enquanto um centro ou metrópole explora várias regiões, uma periferia geralmente mantém relações apenas com um centro, ou mesmo os países centrais entram mais facilmente em conluio, de modo que podem impor os termos de troca para as regiões subdesenvolvidas (BREWER, 1990, p. 165). Pesaria para o estabelecimento dessas relações as condições da inserção da periferia na economia mundial, principalmente da América Latina, que se deu num período em que nos países centrais ocorria a passagem para um desenvolvimento capitalista baseado na mais-valia relativa. Segundo Marini (1973, p. 4):

A oferta mundial de alimentos, que a América Latina contribuiu para criar, e que alcançou seu auge na segunda metade do século 19, será um elemento decisivo para que os países industriais confiem ao comércio exterior a atenção de suas necessidade de meios de subsistência. O efeito dessa oferta (ampliado pela depressão de preços dos produtos primários no mercado mundial, tema a que voltaremos adiante) será o de reduzir o valor real da força de trabalho nos países industriais, permitindo assim que o incremento da produtividade se traduza ali em taxas de mais-valia

5 Segundo Amin (1976, p. 170), "É que, nas formações do capitalismo central, o rendimento dominante é o lucro capitalista, enquanto que, nas do capitalismo periférico, é muitas vezes o rendimento do proprietário fundiário, classe dominante beneficiária da integração no mercado internacional. Numa economia capitalista, os lucros constituem a renda elástica que mais responde às variações da conjuntura. Os lucros excepcionais realizados em períodos de prosperidade são reinvestidos. A liberação de mão-de-obra devida ao progresso é parcialmente compensada pela necessidade suplementar de mão-de-obra para a produção de bens de equipamento. Parcialmente, apenas, dado que o empresário não tem interesse em introduzir uma inovação a não ser que a economia de mão-de-obra seja superior ao dispêndio suplementar de capital. Numa economia agrária integrada no mercado internacional, não é assim. Os rendimentos dos proprietários fundiários, que se elevam em fase de prosperidade, não são investidos, mas gastos (e em grande parte despendidos em bens importados). O progresso na produtividade agrícola não é compensado, mesmo parcialmente, por uma demanda crescente por mão-de-obra para a fabricação de bens de equipamento. [...]. O excedente da oferta de mão-de-obra é portanto relativamente muito maior." 
cada vez mais elevadas. Em outros termos, mediante a incorporação ao mercado mundial de bens-salário, a América Latina desempenha um papel significativo no aumento da mais-valia relativa nos países industriais.

Nos países centrais, esse aumento de produtividade faz com que se eleve a parte constante de seus capitais, ocasionando um aumento em sua composição orgânica. Mesmo com o aumento da mais-valia relativa nesses países, o capital total adiantado cresce mais que proporcionalmente ao aumento da mais-valia, ocasionando uma tendência à queda nas taxas de lucro dos países centrais. Nesse sentido, os países periféricos, como fornecedores de matérias-primas, têm um papel fundamental na superação de tais obstáculos à expansão do capital, uma vez que reduções nos preços dessas mercadorias aparecem como contratendência à queda nas taxas de lucro. Nesse ponto, Marini vê a necessidade de se identificar as causas que levam a um processo contínuo de deterioração dos termos de troca em prejuízo da periferia e porque essa deterioração não leva a um desestímulo à participação desses países nas trocas internacionais. Esse processo de deterioração dos termos de troca está ligado, por sua vez, à forma como se estabelecem os preços dos produtos exportáveis no centro e na periferia, e conteria um mecanismo intrínseco de transferência de valor.

Marini (1973), ao tratar acerca dos mecanismos de transferência de valor, percebe que pode ter tanto uma direção intra quanto intersetorial. Em sua primeira forma, as transferências tendem a ocorrer entre nações concorrentes, produtoras de um mesmo tipo de bem, de modo que se dão entre economias industriais avançadas ou entre economias produtoras de produtos primários. Nas relações entre centro-periferia, no entanto, são as transferências intersetoriais que caracterizam as trocas. As nações avançadas, por produzirem uma classe de mercadoria que os países atrasados não são capazes produzir, têm a capacidade de determinar seus preços de forma a estabelecer uma constante troca desigual. Pode-se compreender que, diferentemente das trocas intrassetoriais entre nações avançadas, que por serem dinâmicas apresentam constantes fluxos e refluxos na transferência de valor, no caso das relações entre países de diferentes graus de desenvolvimento a transferência se dá de maneira contínua e ininterrupta em favor das economias avançadas. O resultado desse processo é que a classe capitalista dos países periféricos fica privada de uma parte da mais-valia gerada internamente, o que se traduz em uma queda em suas taxas de lucro.

Os capitalistas dos países periféricos, para compensar suas perdas, atuam no sentido de aumentar a massa de valor realizado no mercado internacional, o que se traduz em um aumento no grau de exploração da classe trabalhadora dessas regiões. Nesse sentido, conforme se aprofundam as brechas nos preços das mercadorias exportáveis das nações desenvolvidas, os mecanismos de compensação que a classe capitalista lança mão fazem com que a oferta de bens primários dessas 
nações no mercado internacional aumente conjuntamente. A superexploração da classe trabalhadora, que se dá nessas regiões atrasadas como forma de compensação às perdas da classe capitalista, impede, por sua vez, a formação de um mercado interno que dinamize a economia, de modo que se aprofunda a dependência dessas nações em relação ao mercado externo. O comércio internacional significa, assim, para as economias atrasadas, uma drenagem constante de sua renda interna.

Nesse sentido, segundo a teoria marxista da dependência, o desenvolvimento do modo de produção capitalista nos países subdesenvolvidos, e na América Latina em especial, se transforma em desenvolvimento econômico no centro, baseado na mais-valia relativa, no progresso técnico e na dinâmica interna. Nos países atrasados, por outro lado, se transforma em seu oposto, no desenvolvimento do subdesenvolvimento, que tem como característica a produção baseada na mais-valia absoluta, estagnação econômica, falta de progresso técnico, dependência dos mercados consumidores dos países centrais e de suas inovações tecnológicas, etc.

Tem-se, assim, de acordo com as teorias tratadas, que as trocas internacionais e a forma de inserção das economias periféricas na economia mundial estão na base da manutenção de sua condição de baixo desenvolvimento. Essa condição tenderia a perpetuar-se mesmo com os fluxos de capitais do centro, dado que esses se direcionam até periferia com a intenção de reverter os obstáculos à acumulação de capital existente em seus países. Nesse sentido, não inauguram nessas regiões atrasadas um padrão de desenvolvimento econômico como em seus locais de origem, mas se instalam ali justamente para aproveitar as diferenças existentes, principalmente nas remunerações da classe trabalhadora, de forma a aprofundar o desenvolvimento desigual. Esse movimento também priva os países atrasados da possibilidade de investimento, em especial de internalizar o desenvolvimento de progresso técnico, o que relega a uma industrialização que se mantém sempre um passo atrás daquela vista no centro.

Para tais autores, e isso é marcadamente forte para Emmanuel, ${ }^{6}$ a relação de exploração entre centro-periferia torna-se central, se sobrepondo à exploração capital-trabalho. Apesar de nem todos concordarem em relação à exploração, mesmo que indireta, da classe trabalhadora dos países centrais sobre essa mesma classe dos países periféricos, percebem que no centro se torna possível um desenvolvimento capitalista com distribuição de renda. Dessa forma, mesmo que não

$6 \quad$ Segundo Howard e King (1992, p. 192): "Finally, and by far the most important, he [Emmanuel] attacks the notion of international working class solidarity and replaces the class struggle with conflict between rich and poor countries as the central divide in world capitalism. As the chief beneficiaries of unequal exchange, workers in the advanced countries no longer have a common interest with those in backward areas, upon whose continued exploitation their own high living standard depend." 
eliminada, a exploração da classe trabalhadora dos países centrais estaria bastante diminuída. Essa relação entre nações que se estabelece, e os diferentes graus de exploração existentes, limitariam a possibilidade de uma luta internacional da classe trabalhadora, e essa se tornaria quase que exclusivamente uma luta nacional. Tal luta surgiria da impossibilidade de desenvolvimento econômico capitalista na periferia, e não da exploração e das contradições intrínsecas desse modo de produção.

Outro fator comum a tais autores é a consideração da transferência de valor entre centro e periferia como um processo preferencialmente intersetorial. Dessa forma, a periferia deve necessariamente especializar-se em setores distintos daqueles existentes nos países centrais. Ocorre, porém, que caso algumas empresas de setores típicos dos países centrais se instalassem na periferia, e fossem capazes de produzir com um custo de produção menor que o custo médio do setor, obteriam um lucro extraordinário e, assim, teriam transferida para elas, dado o processo intrassetorial de concorrência, parte da mais-valia produzida pelas empresas concorrentes dos países centrais. Mesmo com tais autores considerando que os fluxos internacionais de capital tendem a fazer com que os custos de instalação de uma planta produtiva se aproximem nas distintas regiões, o que torna esse movimento extremamente factível, essa transferência intrassetorial de valor na esfera internacional não é desenvolvida por eles. Nesse sentido, a relação estabelecida entre transferência de valor e subdesenvolvimento deve assentar-se em uma ampla especialização produtiva entre centro e periferia. Para explicar tal relação, os autores recorrem à ação do capital estrangeiro nesses locais, que se instalariam nos países atrasados com o objetivo de produzir de maneira mais barata aquelas mercadorias que servem de matérias-primas ou bens intermediários para a produção em seus locais de origem. ${ }^{7}$ Nesse sentido, os setores mais avançados das economias centrais ficariam restritos a esses países e sua internacionalização rumo à periferia estaria bloqueada.

O processo de transferência de valor, partindo dos vários mecanismos que podem ser derivados da teoria de Marx, apresenta uma dinâmica mais complexa. Alia-se a ele o funcionamento da concorrência, a distinção na composição orgânica entre setores e na produtividade entre empresas e a formação de rendas de monopólios, ${ }^{8}$ para assim propor um quadro mais amplo de tal processo.

$7 \quad$ É recorrente no texto de Marini (1973) a ideia de que os países periféricos, em especial os da América Latina, cumprem uma função estabelecida no comércio internacional. Essa função estaria relacionada ao suprimento das mercadorias necessárias ao processo de acumulação nos países centrais. Segundo Marini (1973, p. 13), "A industrialização latino-americana não cria, portanto, como nas economias clássicas, sua própria demanda, mas nasce para atender a uma demanda pré-existente, e se estruturará em função das exigências de mercado procedentes dos países avançados."

Ver nota 12 . 
Na seção seguinte são expostos tais mecanismos e seus efeitos, principalmente confrontando a relação direta entre transferência de valor e desenvolvimento desigual.

\section{Transferência de Valor e Vantagens Absolutas}

Dentro do processo histórico de desenvolvimento do modo de produção capitalista, o capital mercantil é o primeiro que circula na esfera internacional. Nessa fase inicial, a possibilidade de os países colocarem suas mercadorias no mercado externo está limitada pelas condições internas de cada um deles. Os capitais dos países nos quais o desenvolvimento das forças produtivas deu-se de maneira mais rápida e que, portanto, detiveram vantagens absolutas em uma variedade maior de mercadorias dominaram as trocas internacionais, de modo que os capitais dos países atrasados apenas comercializavam mercadorias de difícil ou mesmo impossível produção nas nações avançadas. Esse padrão de comércio gerou um processo acelerado de acumulação e centralização dos capitais nos países centrais, enquanto relegou aos capitais dos países atrasados diminutas possibilidades de investimento. ${ }^{9} \mathrm{O}$ processo desigual de acumulação do capital criou, assim, as condições para que aqueles capitais situados nos locais de desenvolvimento mais acelerado se expandissem internacionalmente. A internacionalização do capital mercantil passa a dar lugar, assim, à internacionalização do capital industrial em cada uma de suas distintas formas. ${ }^{10}$

O processo concorrencial faz com que o capital se mova intra e intersetorialmente de modo a reduzir os custos de produção e atuar nos setores de maior lucratividade. Esses movimentos que ocorrem na esfera nacional passam a dominar também a esfera internacional, conforme o capital se expande mundialmente. Os países, por sua vez, apresentam-se ao capital com diferentes oportunidades de custos de produção, os quais favorecem o surgimento de diferenciais de lucratividade que alimentam os fluxos internacionais de capital. $\mathrm{O}$ resultado desse processo faz surgir um movimento simultâneo de tendência à diferenciação e à equalização das taxas de lucro. Ainda, o desenvolvimento das forças produtivas e a decorrente tendência declinante da taxa de lucro incentivam a exportação de capital para outros setores e regiões. Segundo a teoria clássico-marxista das vantagens absolutas e da concorrência, é em favor dessas possibilidades de valorização que o capital se move na esfera internacional.

9 Como os capitais dos países avançados dominam os setores produtivos daquelas mercadorias consumidas em ambas as nações, para os capitais dos países atrasados restariam poucos setores para investirem seus capitais, portanto tendem a concentrar-se naquelas atividades que estão ligadas a características naturais e específicas de seus países.

10 Segundo Marx (1984), o capital industrial é aquele que em seu circuito assume as formas de capital-dinheiro, capital produtivo e capital-mercadoria. 
Ocorre, no entanto, que as diferenças no desenvolvimento das forças produtivas dos capitais nos distintos países fazem com que aqueles localizados nas regiões mais avançadas dominem o processo concorrencial e os fluxos de capitais nessa esfera. Esses capitais, dado o domínio de técnicas mais avançadas e maior magnitude, acabam por se sobrepor aos capitais locais das regiões atrasadas. Esses movimentos também desencadeiam tendências de especialização e diversificação produtiva, de forma que as diferenças intrassetoriais de produtividade também passam a refletir as diferenças de localização da produção. Os capitais nas nações desenvolvidas, ao encontrarem possibilidades de valorização nas atividades típicas dos países atrasados, irão se direcionar a tais locais e tais atividades. Essas podem atrair os capitas tanto por apresentarem uma maior taxa de lucro, quanto pela possibilidade desses de implantarem novas técnicas e produzirem com um custo menor que o custo médio. Esse movimento impulsiona a especialização produtiva entre distintas nações e favorece os movimentos intersetoriais de transferência de valor. Por outro lado, na medida em que as nações oferecem oportunidades de custos distintas aos capitais, outros ramos produtivos tornam-se viáveis de internacionalização. Mesmo atividades estritamente nacionais passam a ser alvo do capital externo e podem ter seu mercado expandido na esfera internacional. Assim como nacionalmente em um mesmo setor atuam empresas com distintas produtividades, a internacionalização fará com que distintas empresas de distintas produtividades, em um mesmo setor, se localizem em diferentes países. Esse fator colabora para uma transferência intrassetorial de valor. Essas transferências, apesar de aparecerem como transferências entre países, nada mais são do que o resultado do processo concorrencial entre capitais de distintas produtividades e composições orgânicas (SHAIKH, 1991a, p. 217-218).

A internacionalização do capital favorece, assim, dois movimentos de transferência de valor, fruto das duas formas que a concorrência entre capitais assume, e que facilmente podem apresentar direções opostas. Os investimentos externos geram o que Shaikh (1991a, p. 208) identifica como uma "[...] estructura típicamente dualista de las exportaciones de los países capitalistas subdesarrollados [...]”. Essa estrutura se caracteriza pela existência conjunta de setores modernos com elevada produtividade e composição orgânica e setores mais atrasados com baixo grau de desenvolvimento tecnológico. As transferências de valor têm, assim, tal estrutura como base, o que fortalece a necessidade de se compreender esse fenômeno a partir dos diferentes capitais que atuam internacionalmente.

A partir do exemplo de Carchedi (1991, p. 243-246), pode-se demonstrar esses dois movimentos de transferência de valor. Tomando-se os capitais localizados na Itália e França, divididos em quatro setores (A, B, C e D), temos que as mercadorias dos ramos A e B são produzidas em ambos os países, enquanto que as dos ramos $\mathrm{C}$ e D são exclusividade da Itália e da França respectivamente. De 
acordo com os dados da Tabela 3, a produção no ramo A, na Itália, apresenta uma maior composição orgânica, de forma que os capitais de produtividade modal nesse país serão também os capitais modais internacionalmente. Na França, são os capitais do ramo B que apresentam uma maior composição orgânica, e, assim, são seus capitais modais que regulam os preços de produção na esfera internacional. Enquanto na Itália uma nova tecnologia já foi implementada no ramo A, de modo que as empresas III desse setor (AIII) apresentam produtividade acima da média, na França a tecnologia mais avançada nesse setor é apenas a modal na Itália. O inverso ocorre na França para o ramo B: enquanto parte dos capitais aplicados nesse setor produzem com capacidade acima da média, na Itália a técnica mais avançada é apenas a modal na França. Pode-se dizer, assim, que a Itália detém uma vantagem absoluta na produção das mercadorias do ramo A e a França nas mercadorias do ramo B. Nos ramos C e D, apesar da diferente composição orgânica entre eles, não há indicação de uma maior ou menor produtividade, dada a natureza distinta de suas mercadorias (CARCHEDI, 1991, p. 245). Há, portanto, os seguintes valores expostos na Tabela 3: VI representa o valor individual produzido por cada unidade de capital; P é o produto por unidade de capital; VTR é o valor tendencialmente realizado por unidade de capital (valor realizado quando todas as mercadorias são vendidas pelos preços de produção dos produtores modais); e VTR - V é a transferência de valor dada a formação dos preços de produção.

Tabela 3 - Formação dos preços de produção na esfera internacional

\begin{tabular}{|c|c|c|c|}
\hline \multicolumn{4}{|c|}{ Itália } \\
\hline & Empresa I & Empresa II & Empresa III \\
\hline Ramo A & Abaixo da média & Modal & Acima da média \\
\hline VI & $\begin{array}{c}75 c+25 v+25 m v \\
=125\end{array}$ & $\begin{array}{c}80 c+20 v+20 m v \\
=120\end{array}$ & $\begin{array}{c}85 \mathrm{c}+15 \mathrm{v}+15 \mathrm{mv} \\
=115\end{array}$ \\
\hline $\mathrm{P}$ (un) & 90 & 100 & 110 \\
\hline VTR & 112,85 & 125,4 & 137,92 \\
\hline VTR - V & $-12,15$ & 5,4 & 22,92 \\
\hline Ramo B & Abaixo da média & Abaixo da média & Modal \\
\hline VI & $\begin{array}{c}80 \mathrm{c}+20 \mathrm{v}+20 \mathrm{mv} \\
=120\end{array}$ & $\begin{array}{c}85 \mathrm{c}+15 \mathrm{v}+15 \mathrm{mv} \\
=115\end{array}$ & $\begin{array}{c}90 \mathrm{c}+10 \mathrm{v}+10 \mathrm{mv} \\
=110\end{array}$ \\
\hline $\mathrm{P}$ (un) & 50 & 55 & 60 \\
\hline VTR & 104,48 & 114,93 & 125,4 \\
\hline VTR - V & $-15,52$ & $-0,07$ & 15,4 \\
\hline
\end{tabular}


conclusão.

\begin{tabular}{|c|c|c|c|}
\hline \multicolumn{4}{|c|}{ Itália } \\
\hline & Empresa I & Empresa II & Empresa III \\
\hline Ramo C & Abaixo da média & Modal & Acima da média \\
\hline VI & $\begin{array}{c}65 c+35 v+35 m v \\
=135\end{array}$ & $\begin{array}{c}70 c+30 v+30 m v \\
=130\end{array}$ & $\begin{array}{c}75 \mathrm{c}+25 \mathrm{v}+25 \mathrm{mv} \\
=125\end{array}$ \\
\hline $\mathrm{P}$ (un) & 50 & 60 & 70 \\
\hline VTR & 104,48 & 125,4 & 146,27 \\
\hline VTR -V & $-30,52$ & $-4,6$ & 21,27 \\
\hline
\end{tabular}

França

\begin{tabular}{|c|c|c|c|}
\hline & Empresa I & Empresa II & Empresa III \\
\hline Ramo A & Abaixo da média & Abaixo da média & Modal \\
\hline VI & $\begin{array}{c}70 c+30 v+30 m v \\
=130\end{array}$ & $\begin{array}{c}75 \mathrm{c}+25 \mathrm{v}+25 \mathrm{mv} \\
=125\end{array}$ & $\begin{array}{c}80 c+20 v+20 m v \\
=120\end{array}$ \\
\hline$P$ (un) & 85 & 90 & 100 \\
\hline VTR & 106,57 & 112,84 & 125,4 \\
\hline VTR - V & $-23,43$ & $-12,16$ & 5,4 \\
\hline Ramo B & Abaixo da média & Modal & Acima da média \\
\hline VI & $\begin{array}{c}85 \mathrm{c}+15 \mathrm{v}+15 \mathrm{mv} \\
=115\end{array}$ & $\begin{array}{c}90 \mathrm{c}+10 \mathrm{v}+10 \mathrm{mv} \\
=110\end{array}$ & $\begin{array}{c}95 c+5 v+5 m v= \\
105\end{array}$ \\
\hline$P$ (un) & 55 & 60 & 70 \\
\hline VTR & 114,93 & 125,4 & 146,27 \\
\hline VTR - V & $-0,07$ & 15,4 & 41,27 \\
\hline Ramo D & Abaixo da média & Modal & Acima da média \\
\hline VI & $\begin{array}{c}60 c+40 v+40 m v \\
=140\end{array}$ & $\begin{array}{c}65 c+35 v+35 m v \\
=135\end{array}$ & $\begin{array}{c}70 c+30 v+30 m v \\
=130\end{array}$ \\
\hline $\mathrm{P}$ (un) & 120 & 130 & 140 \\
\hline VTR & 115,73 & 125,4 & 135 \\
\hline VTR - V & $-24,27$ & $-9,6$ & 5 \\
\hline
\end{tabular}

Fonte: Carchedi (1991, p. 244).

Assumindo o processo concorrencial, os preços de produção nesse exemplo são regulados pelos capitais modais de cada setor e a taxa de lucro tende a equalizar-se. O capital social total dos dois países em conjunto (D) é de $\$ 1800,00$, em que 
cada capitalista individual adianta uma quantidade igual a $\$ 100,00$. A produção total de mais-valia, considerando-se os dois países, é de $\$ 405,00$, de modo que obtém-se a taxa média de lucro (MV/D) igual a $\$ 405 / \$ 1800=22,5 \%$. Dessa forma, cada produtor modal tenderia a realizar um valor igual a $\$ 122,5$ para cada $\$ 100,00$ de capital adiantado. Dividindo esse valor pela quantidade de mercadorias que os capitais modais de cada setor produzem, obtém-se seus preços unitários de produção. No entanto, a partir desses cálculos, o valor tendencialmente realizado (preços unitários em cada setor multiplicado pelo total de mercadorias vendidas) nesse exemplo seria de $\$ 2154,00$, enquanto que o valor produzido é de $\$ 2205,00$. Para corrigir essa disparidade, o autor aplica uma razão de distribuição dada por $\$ 2205$ / \$2154 = 1,0237 e assim deriva os preços de produção ajustados por unidade de capital. Esses passam a ser iguais a $\$ 122,5 \times 1,0237=\$ 125,4$ sendo, portanto, a taxa média de lucro desse exemplo igual a $25,4 \%$.

Todos os capitais modais realizarão um valor igual a $\$ 125,4$ por unidade de capital, de forma que apenas esses capitais se apropriam do lucro médio. Para cada setor, os preços unitários de suas mercadorias serão iguais ao valor tendencialmente realizado pelos capitais modais dividido pela quantidade de mercadorias produzidas por esses capitais (VTRmodal / Pmodal). Dado o processo intrassetorial de concorrência, esses preços unitários serão praticados tanto pelos capitais que produzem acima, quanto abaixo da média, não importando o país em que se localizem. A composição orgânica média (C/V) desse exemplo é de 3,44, de modo que nenhum capital representado opera com composição igual à média. A distribuição da mais-valia nessa economia respeitará, assim, tanto as diferenças nas composições orgânicas de cada setor, quanto as diferentes produtividades intrassetoriais. No caso dos capitais modais, aqueles que operam com uma composição acima da média estarão se apropriando de uma mais-valia maior que aquela produzida internamente: são os casos dos capitais AII e BIII, na Itália, e AIII e BII na França. O oposto ocorre com aqueles capitais modais que operam com composição abaixo da média, CII e DII, que realizarão uma mais-valia menor que a produzida por eles.

No caso dos capitais não modais, no entanto, isso não ocorre. Nesse sentido, influi não apenas a composição orgânica desses capitais em relação à composição orgânica média dessa economia, mas também sua posição em relação à produtividade das demais empresas que atuam no mesmo setor. Dessa forma, mesmo um capital individual com composição orgânica maior que a média, porém que apresente produtividade baixa em relação a seus concorrentes, poderá realizar uma mais-valia menor que a produzida internamente. Como se pode ver, por exemplo, os produtores representados por BII na Itália, apesar de apresentarem composição orgânica igual a 5,67, ou seja, acima da média, realizam uma mais-valia menor que a produzida por eles. As transferências líquidas de valor devem considerar, 
portanto, ambos os efeitos. Nota-se, ainda, que apesar de intrassetorialmente os capitais apresentarem divergências em suas taxas de lucro, como setores todos realizam o lucro médio. As transferências de valor respeitam, assim, tanto características intrassetoriais (produtividade), quanto intersetoriais (composição orgânica), segundo Shaikh (1991b, p. 209):

Las transferencias netas de valor involucradas son, no obstante, las resultantes de dos distintos tipos de transferencias: intra-industria, que dependen de las diferencias entre productores individuales y productores promedio dentro de la misma industria; e inter-industria, que dependen de diferencias en las composiciones orgánicas de los productores medios en diferentes industrias. Para cualquier conjunto individual de capitales, definido, por ejemplo por su localización, nacionalidad o grado de desarrollo, la transferencia neta de plusvalía será la suma de los dos efectos.

Uma vez que esses dois efeitos, que operam simultaneamente, podem apresentar direções contrárias, a transferência líquida de valor pode ser zero, mesmo para um capital que opere em um setor de baixa composição orgânica, porém com elevada produtividade em relação a seus concorrentes. Considerando a estrutura dual do setor exportador das economias atrasadas, como tratado por Shaikh, e esses dois movimentos de transferência de valor, é possível que um país atrasado apresente uma transferência de valor baixa ou mesmo nula. Uma vez que os investimentos diretos externos contribuem para a formação de um setor moderno e altamente produtivo, principalmente naqueles ramos nos quais os países atrasados detêm vantagens absolutas, tais investimentos poderiam, na verdade, amenizar ou mesmo interromper as transferências líquidas de valor das regiões atrasadas para as avançadas.

Outro ponto central para as teorias marxistas tratadas na seção anterior são os efeitos dos diferenciais de salários entre as economias avançadas e atrasadas. Esses diferenciais, aliados a um processo global de equalização das taxas de lucro, formariam a base do processo de trocas desiguais. Pesa também, nesse sentido, a ampla especialização produtiva suposta por tais autores, de forma que a concorrência intraindústrias se daria preferencialmente entre países com um mesmo grau de desenvolvimento econômico. Ocorre, no entanto, que tal abordagem favorece a interpretação do tempo de trabalho necessário e excedente apenas em suas diferenças quantitativas, e não em suas diferenças qualitativas. Nesse sentido, nível salarial e duração da jornada de trabalho seriam suficientes para demonstrar uma maior exploração e produção de valor nos países atrasados. Marx (1986, p. 14546), por outro lado, coloca que:

Em cada país vale certa intensidade média do trabalho, abaixo da qual o trabalho necessário para a produção de uma mercadoria consome mais tempo que o socialmente necessário, e por isso não conta como traba- 
lho de qualidade normal. Apenas um grau de intensidade que se eleva acima da média nacional, num país dado, muda a medida do valor pela mera duração do tempo de trabalho. Não ocorre o mesmo no mercado mundial, cujas partes integrantes são os vários países. A intensidade média do trabalho muda de país para país; é aqui maior, lá menor. Essas médias nacionais constituem assim uma escala, cuja unidade de medida é a unidade média do trabalho universal. Comparando com o menos intensivo, o trabalho nacional mais intensivo produz pois, em tempo igual, mais valor; que se expressa em mais dinheiro. Porém a lei do valor é modificada ainda mais em sua aplicação internacional pelo fato de que no mercado mundial o trabalho nacional mais produtivo conta também como mais intensivo, sempre que a nação mais produtiva não seja obrigada pela concorrência a reduzir o preço de venda de sua mercadoria a seu valor. (MARX, 1986, p. 145-46).

Nesse sentido, o salário na esfera internacional, dentro da análise de Marx, não importa tanto em sua forma nominal, mas sim em relação ao total de valor que cria, ou seja, importa a relação entre tempo de trabalho necessário e tempo de trabalho excedente. Caso um país apresente elevada intensidade e produtividade do trabalho, de forma que conte como trabalho potenciado, mesmo com um nível maior de salário nominal a taxa de mais-valia nesse país pode ser maior que em países de baixos salários e extensas jornadas de trabalho. ${ }^{11}$ Apenas em condições de idênticas composições orgânicas e mesma produtividade, as diferenças nos níveis salariais na esfera internacional aparecem como sinônimo de diferenças no grau de exploração.

Bettelhein (EMMANUEL, 1976, p. 43) argumenta que, como em alguns setores os investimentos diretos externos são capazes de gerar na periferia estruturas produtivas idênticas às do centro, os menores salários e os menores custos de produção decorrentes passam a significar, mesmo que momentaneamente, um lucro extraordinário a esses capitais. Nesse sentido, menores salários seriam responsáveis por uma transferência de valor em direção inversa àquela tratada pelas teorias marxistas tradicionais.

11 Segundo Marx (1986, p. 146): "Na medida em que a produção capitalista é desenvolvida num país, na mesma medida elevam-se aí também a intensidade e a produtividade nacional do trabalho acima do nível internacional. As diferentes quantidades de mercadorias da mesma espécie, que são produzidas em tempo igual de trabalho em diferentes países, têm, portanto, valores internacionais desiguais, que se expressam em preços diferentes, isto é, em somas diferentes de dinheiro conforme os valores internacionais. O valor relativo do dinheiro será portanto menor na nação em que o modo de produção capitalista é mais desenvolvido do que naquela em que é menos desenvolvido. Segue, portanto, que o salário nominal, o equivalente da força do trabalho expresso em dinheiro, será também mais alto na primeira nação que na segunda; o que de forma alguma significa que isso também é válido para o salário real, isto é, para os meios de subsistência colocados à disposição do trabalhador. Porém, mesmo abstraindo essa diferença relativa do valor do dinheiro em diferentes países, será freqüentemente verificado que o salário diário, semanal etc. na primeira nação é mais alto que na segunda, enquanto o preço relativo do trabalho, isto é, o preço do trabalho em relação tanto à mais-valia como ao valor do produto, na segunda nação é mais alto que na primeira." 
Shaikh (1991a, p. 211-213), por sua vez, trata tal questão de forma a demonstrar como os diferenciais de salários são condizentes com uma taxa líquida de transferência intrassetorial de valor baixa ou mesmo nula. Em primeiro lugar, o autor supõe que os países avançados apresentam altos salários e altas taxas de mais-valia, enquanto as economias atrasadas aliam baixos salários com baixas taxas de mais-valia, sendo que tanto salário médio, quanto taxa de mais-valia mundial são constantes no tempo. A partir disso, o autor coloca que, no caso das transferências de valor no interior de uma mesma indústria,

Para cualquier capital individual un cambio en su tasa de plusvalía cau-
sado por un cambio en la tasa de salario alterará la división de la jorna-
da de trabajo en tiempo de trabajo necesario y excedente. Pero esto no
cambiará en sí misma la duración de la jornada de trabajo y, por lo tanto,
no modificará el valor agregado por el trabajo vivo; tampoco cambia el
valor transferido por este trabajo. Los cambios del salario, en otras pala-
bras, modifican la rentabilidad de capitales individuales pero no su pro-
ductividad; dejan intacta la estructura de los valores individuales y valores
sociales. De esto se concluye que los diferenciales de salarios entre países
no tienen ningún efecto en las transferencias de valor intra-industria oca-
sionada por la formación de valores sociales (SHAIKH, 1991a, p. 211).

No caso das transferências intersetoriais de valor, os diferenciais de salários, aliados à estrutura dualista das exportações dos países subdesenvolvidos, irão potencializar os dois fluxos de transferência de valor de modo que "[...] es aún perfectamente posible obtener una transferencia neta de plusvalía igual a cero, entre países [...]" (SHAIKH, 1991a, p. 212). Isso se dá porque diferenças salariais, mesmo que não alterem a taxa média de lucro mundial, tendem a gerar efeitos opostos nas indústrias que compõem a estrutura dualista das exportações dos países subdesenvolvidos. Dentro de tal estrutura, os ramos modernos de alta composição orgânica desses países tendem a ser, também, os mais produtivos mundialmente, o oposto naqueles ramos de baixa composição que participam das trocas internacionais. Em comparação com o salário médio mundial, os baixos salários do setor moderno dessas economias levam a uma diminuição ainda maior dos custos de produção, de forma que aumenta a apropriação de mais-valia por parte das empresas desses setores tanto pelo fato de sua maior composição orgânica, quanto pelo menor custo de produção em relação a seus concorrentes. No caso dos setores de baixa composição orgânica e baixa produtividade, os diferenciais de salários acabam por potencializar a transferência da mais-valia criada neles. Shaikh (1991a, p. 213) conclui, assim, que:

Lo importante de todo esto es que el subdesarrollo de los países subdesarrollados no necesariamente implica una transferencia negativa de valor de su parte. Ello sólo sirve para subestimar la cuestión más importante de que el desarrollo desigual ocasionado por la competencia internacio- 
nal yace en el centro de la cuestión, y no alguna transferencia de valor que pueda o no resultar de este desarrollo desigual.

Um terceiro mecanismo de transferência de valor via formação de preços se dá naquelas mercadorias sujeitas à formação de rendas, devido a alguma situação de monopólio. ${ }^{12}$ Essas rendas estão intimamente ligadas a grande parte da produção para exportação dos países subdesenvolvidos. A formação de rendas de monopólio não estão sujeitas unicamente à produção agrícola e mineral, podendo também aparecer na produção industrial. Ocorre, no entanto, que como a produção industrial é muito mais passível de deslocamento do que a produção agrícola, as rendas nesse setor e as transferências de valor devido a elas também se deslocalizam conforme muda o local da produção. Dessa forma, mesmo que um capital de um país central obtenha rendas na produção industrial, se esse capital estiver aplicado em um país atrasado será em direção a esse país que ocorrerá uma transferência de valor via o preço de suas mercadorias. Se esse valor é depois retransferido ao capitalista do país central, esse processo não ocorrerá através do mecanismo de preços.

Os investimentos diretos externos podem, ainda, pesar de outra maneira em favor das transferências de valor via formação de rendas para os países subdesenvolvidos. Nesse caso, importa a diferenciação que Marx faz da renda diferencial de tipo I e a renda diferencial de tipo II. Se a primeira está relacionada ao investimento de um mesmo montante de capital em terras de distintas produtividades, a segunda tem sua origem da inversão de distintos montantes de capital sobre terras de mesma qualidade. Nesse sentido, a renda diferencial de tipo II está relacionada com o desenvolvimento das forças produtivas na produção agrícola e mineral. Como os capitais estrangeiros dos países desenvolvidos tendem a possuir uma capacidade maior de investimento, uma vez que passam a agir nessas atividades típicas das regiões atrasadas elevam ali a produtividade através de um aumento em sua composição orgânica. Dessa forma, alimentam o surgimento da renda diferencial de tipo II nesses locais, o que fomenta a transferência de valor via preços dessas mercadorias. Essas transferências são um caso especial das transferências intersetoriais de valor, mas que, dado sua origem distinta, devem ser consideradas separadamente no estudo das transferências líquidas de valor entre regiões.

12 Tais situações de monopólio são tratadas por Marx nos capítulos sobre a renda da terra no livro III de O Capital e também nos Grundrisse (MARX, 1973). O monopólio existe quando o acesso a um fator de produção, que confere alguma vantagem ao capitalista que o detém, não está acessível a todos os capitalistas que atuam no mesmo ramo de produção. Dessa forma, a aplicação de uma mesma quantidade de capital em um mesmo setor pode gerar valores distintos, o que dá origem à formação de rendas. O exemplo principal utilizado por Marx é a terra, recurso escasso e limitado, no entanto o monopólio de uma tecnologia, máquina, marca, etc. também pode ser responsável pelo surgimento dessas rendas. 
O tratamento acerca dos inúmeros mecanismos de transferência de valor entre os capitais via preços, dado pela teoria clássico-marxista das vantagens absolutas, levanta, assim, uma nova perspectiva a respeito da relação entre essas transferências e o subdesenvolvimento. Não busca, no entanto, fazer apologias à ação do capital estrangeiro nos países subdesenvolvidos. Como será visto na próxima seção, os resultados desses fluxos são ambíguos tanto para as nações periféricas, quanto para as nações centrais. Entende, por outro lado, que o aprofundamento do capital na esfera internacional, em todas suas formas, tende a fortalecer as contradições inerentes à relação capital-trabalho tanto nas economias avançadas, quanto nas atrasadas. Os efeitos dessa internacionalização do capital tornam cada vez mais restrita a capacidade de explicação daquelas teorias que procuram entender o desenvolvimento do modo de produção capitalista a partir da ação dos Estados e das nações, e não o contrário. Essa visão acaba por distorcer certas categorias marxistas, a ponto de, em alguns casos, propor o fim da exploração entre classes e torná-la um fenômeno entre nações, como proposto por Emmanuel (1976). Por colocar a nação como categoria central de análise, não é capaz de explicar a partir do movimento do capital e de sua busca por valorização, seus fluxos e refluxos. Utiliza, por exemplo, os diferenciais das taxas de lucro e dos custos de produção para explicar a vinda de investimentos direto externos para os países atrasados, mas não faz o mesmo para explicar a repatriação dos lucros aos países avançados e o maior nível de investimento direto externo entre eles.

A teoria das vantagens absolutas, por outro lado, procura argumentar que os fluxos de capitais devem ser entendidos a partir do processo concorrencial intrínseco à acumulação de capital. Esse processo é em si desigual e supõe que os capitais apresentarão dinâmicas distintas de desenvolvimento. Nas nações desenvolvidas, por exemplo, onde o desenvolvimento das forças produtivas encontra-se em estágio mais avançado, o decorrente aumento de produtividade pode significar uma capacidade maior das empresas e ramos que operam nesses locais de se desviarem da taxa de lucro média. Esse fator causaria, por sua vez, um fluxo de capitais que pode assumir a forma de remessas de lucros, transferência de capital, etc. Nesse sentido, o que aparece com um processo de espoliação entre nações é compreendido, na verdade, como a expressão mundial do processo de valorização do capital. Esse processo se dá, no entanto, dentro das condições materiais que variam nos distintos locais e assim desencadeiam tendências de convergência e divergência que se refletem em um amplo desenvolvimento desigual. Um desenvolvimento capitalista desigual que, no entanto, antes de ser desigual entre nações é desigual entre as distintas classes sociais que o compõe. 


\section{Considerações acerca do Desenvolvimento Desigual}

Na seção anterior, a relação direta proposta pelas teorias marxistas tradicionais entre transferência de valor e subdesenvolvimento foi questionada. Como alternativa se propôs que o capital se move em busca de produzir com menores custos e para onde as taxas de lucro são maiores, logo seu motor não está na transferência de mais-valia. Mesmo setores que tendem a realizar um valor menor do que aquele produzido internamente podem ser alvos dos fluxos de capitais, na medida em que apresentem possibilidades atraentes de valorização ao capital. Ocorre, no entanto, que os setores produtivos detêm características e dinâmicas distintas e, desse modo, se desenvolvem de maneira desigual.

As nações se apresentam ao capital como a base concreta de sua valorização. Condições específicas farão com que algumas atividades se desenvolvam em determinados locais enquanto outras fiquem impossibilitadas de se desenvolver nesses mesmos lugares. Fatores internos de cada nação determinarão, assim, distintas estruturas de custos para os vários ramos produtivos. Nos setores, por exemplo, em que a composição orgânica é baixa e o peso do salário é alto em relação ao capital adiantado, os países com baixos salários apresentarão vantagens em relação à expansão dos capitais que operam nessas atividades. Conforme o capital aprofunda sua atuação na esfera internacional, irá se aproveitar dessas diferenças entre os espaços de valorização, desencadeando tendências de divergência e convergência. Segundo Weeks (1999, p. 2):

We explain divergence in terms of primary and secondary uneven development. Primary uneven development arises because of the more dynamic expansion of capitalist countries relatively to countries in which capitalism is incipient. This difference is inherent in the social relations of capital. Secondary uneven development occurs within the group of predominantly capitalist countries, due to competition and adoption of technical innovations within the social relations of capital. The former generates divergence; the latter exhibits a cyclical pattern of convergence and divergence, with convergence the long term tendency.

Brewer (1990, p. 194) propõe, na mesma direção, a explicação dos diferenciais de produtividade entre nações, colocando também que a mobilidade de capital tende a gerar efeitos de convergência:

A major part of the answer must surely lie in external economies: conditions of production that an individual enterprise either cannot provide for itself or need not provide where the industry is already well established. Examples are a skilled labour force, a network of suppliers, suitable transport services, and so on. These are, of course, all reasons why it is difficult (i.e. in a capitalist context, costly and hence unprofitable) to establish production in a new location. In the earlier parts of the 
imperialist stage, say around 1900, when wages in the centre were still fairly low and technology was still largely in the hands of skilled workers rather than being systematized and brought fully under the control of capital (cf. Braverman 1974), it is easy to see that there was little incentive for established capitalist firms in the centre to shift production to the periphery. In the present stage, however, wage differentials are large, and multinational firms have great experience of transferring technology, so it is much harder to see why a productivity gap should persist (BREWER, 1990, p. 194).

O desenvolvimento dessas economias externas, citadas por Brewer, está relacionado a fatores históricos que determinaram dinâmicas distintas no modo como as relações capitalistas de produção se estabeleceram em cada país. Pesa, nesse sentido, aquilo que Weeks (1999) chama de desenvolvimento desigual primário. Nos países desenvolvidos, as relações capitalistas típicas, como a separação dos produtores de seus meios de produção, o assalariamento e a produção de mercadorias, ocorreram antes e de maneira mais abrangente que nas regióes atrasadas. Essa separação dos produtores de seus meios de produção, tornando ambos elementos do capital, possibilitaram que este se tornasse livre para operar e desenvolver os mais diversos ramos de produção. Dessa maneira, nessas economias avançadas, a expansão do capital fez com que uma grande variedade de atividades produtivas fossem postas sob a relação capital-trabalho. Onde essa separação não ocorreu, ou se deu apenas de maneira tardia, as relações pré-capitalistas de produção tornaram o trabalho e os meios de produção fixos em atividades tradicionais. O próprio sistema colonial, que favorecia a permanência dessas relações, tornava o processo de acumulação de capital bastante restrito e concentrado em poucas atividades. Essas diferenças determinaram a primeira divisão entre países avançados e atrasados, de forma a acompanhar as dinâmicas distintas de desenvolvimento entre as nações, mesmo quando as relações capitalistas de produção se generalizaram na maioria das atividades produtivas das regiões atrasadas.

O desenvolvimento desigual secundário surge, por sua vez, da própria dinâmica da concorrência entre os capitais, no modo de produção capitalista. Esse desenvolvimento desigual cria, no entanto, movimentos contínuos de convergência e divergência. Quando analisada a concorrência em sua forma intrassetorial, percebe-se que convivem simultaneamente empresas de distintas produtividades e, consequentemente, com distintas taxas de lucro. Essas diferenças estão ligadas ao próprio modo como opera a racionalidade capitalista. A implantação de novas técnicas produtivas está sempre relacionada ao cálculo entre a perda do capital instalado e os ganhos devidos a essa nova técnica. Essas perdas e ganhos aparecem de maneira distinta entre os vários produtores de um setor, devido às formas concretas de existência dos distintos capitais individuais. Tais diferenças alimentam um processo desigual de desenvolvimento entre as várias empresas de um mes- 
mo setor (WEEKS, 1999, p. 8). Uma vez que as dinâmicas intra e intersetoriais de concorrência existem como faces de um mesmo processo, as empresas ou setores capazes de obter um lucro acima do lucro médio poderão desencadear fluxos de capitais entre setores, o que pode significar o declínio de certas atividades e a ascensão de outras. Nesse sentido, diferentemente da teoria neoclássica das vantagens relativas e de algumas teorias marxistas, como as mencionadas anteriormente, que veem na falta de concorrência e na formação de monopólios a base de um desenvolvimento desigual entre capitais e nações, entende-se aqui que é a própria concorrência, como fenômeno intrínseco à acumulação de capital, que gera tais disparidades.

$\mathrm{Na}$ medida em que o capital se expande internacionalmente, faz com que tais movimentos, decorrentes do processo concorrencial, atuem nas mais variadas partes do globo e nos mais distintos setores. Pesa, assim, as vantagens absolutas que cada capital pode explorar nas diferentes regiões e que, dessa forma, definirão dinâmicas distintas de desenvolvimento. A questão central nesse ponto não é a transferência de valor, mas sim a capacidade desses setores, localizados em diferentes países, de atraírem o capital e desenvolverem as forças produtivas locais. O próprio desenvolvimento das forças produtivas pode reverter a posição das vantagens absolutas de determinado país, uma vez que torne mais vantajosa a produção em outra localidade, promovendo um declínio da produção mesmo em setores tradicionais. Nesse sentido, o atraso relativo de uma região pode se aprofundar conforme suas características específicas deixem de ser centrais nas vantagens absolutas de custos, ou mesmo conforme os setores que ali se desenvolveram deixem de ser necessários à valorização do capital. A concorrência tende, assim, a aprofundar o desenvolvimento desigual entre capitais, que se expressa num desenvolvimento desigual entre nações.

Ocorre, no entanto, que o acirramento da concorrência na esfera internacional também gera tendências de convergência na medida em que se generalizam, nas mais diversas nações, as relações capitalistas de produção. O capital, ao se aproveitar das distintas vantagens absolutas de custos, gera tanto a possibilidade de desenvolvimento das forças produtivas nos locais atrasados, quanto a instalação de uma maior variedade de ramos produtivos. Dessa forma, acaba por aliviar a balança comercial desses países, aumentar a demanda por trabalho e criar economias externas que podem fomentar ainda mais os fluxos de capitais e os investimentos nesses locais.

No entendimento aqui proposto, o tratamento da competição entre capitais como processo dinâmico, intrínseco à acumulação de capital, está, assim, na base do entendimento do desenvolvimento desigual. A competição a nível internacional, ao possibilitar que os capitais se aproveitem dos diferenciais entre os países, pode significar o desenvolvimento relativo dessas nações ou seu total atraso. Algu- 
mas regiões, capazes de oferecer vantagens absolutas ao capital internacional, poderão apresentar ganhos de produtividade e uma complexificação de sua economia, enquanto outras, ao não serem capazes, podem vir a perder até mesmo suas atividades tradicionais ou as poucas atividades que ali se desenvolveram. Dessa forma, quanto menos um país se torna atraente ao capital, mais fica relegado a desenvolver aquelas poucas atividades em que tem vantagens absolutas graças a questões naturais como clima, fertilidade do solo, reservas minerais, etc. Não se nega, no entanto, que se alguma região atrasada apresentar ou desenvolver internamente vantagens à valorização do capital, poderá experimentar um acelerado desenvolvimento econômico. Esse movimento é, no entanto, mais difícil dada a herança do desenvolvimento desigual primário. Para as regiões desenvolvidas, o processo concorrencial também pode gerar distúrbios e retrocessos. Como todo capital compete entre si, não importando onde esteja localizado, sua internacionalização pode significar a desarticulação de certos setores e atividades tradicionais nos países desenvolvidos. Esse movimento cria prejuízos aos capitais que ali permanecem e, principalmente, a sua classe trabalhadora, que se vê ameaçada pelos salários baixos de outros locais.

O processo de internacionalização do capital aprofunda, assim, as contradições intrínsecas ao modo de produção capitalista. Os resultados da lei geral da acumulação capitalista aceleram-se como processo global, fazendo com que tanto a força de trabalho, quanto o exército industrial de reserva apresentem-se como categorias mundiais à disposição do capital nessa esfera ampliada. Dessa forma, a análise ao nível da nação é insuficiente quando aponta para um processo de desenvolvimento capitalista no qual necessariamente se cria uma polarização entre centro e periferia. Não se procura com isso negar o desenvolvimento desigual entre nações, mas sim restabelecer a centralidade do desenvolvimento desigual entre classes e capitais.

Nesse sentido, também é necessário considerar de outra maneira o conceito de convergência. É comum, nas ciências econômicas, encará-lo como a capacidade, ou não, de se gerar um desenvolvimento econômico nos países atrasados com as características do que o modo de produção capitalista foi durante um período de sua história, nos países centrais. ${ }^{13}$ No entanto, conforme os entraves à expansão do capital vão sendo superados, a convergência assume seu caráter de generalizar a exploração do capital sobre o trabalho em nível global. Características até então tipicamente relacionadas a países periféricos, como concentração de renda, altas taxas de desemprego, quedas salariais e déficits comerciais também passam a apresentar-se nos países centrais. Dessa forma, ao mesmo tempo que se pode falar

13 Principalmente as características de desenvolvimento econômico nos países centrais durante o pós-guerra até meados da década de 1970, um período que aliou crescimento econômico, distribuição de renda, ampliação dos serviços públicos, etc. 
em certa convergência no grau de desenvolvimento das forças produtivas entre algumas regiões antes marcadamente separadas, também se pode falar de um aprofundamento na brecha e na polarização entre as classes sociais em todos os países sujeitos às relações capitalistas de produção e à ação do capital internacional. Restabelece-se, assim, a necessidade de pensar o proletariado como classe mundial, enquanto que as visões de que as mudanças sociais devem necessariamente ser um fenômeno com origem na periferia se afastam de sua validação histórica.

\section{Considerações Finais}

A partir da abordagem proposta neste artigo entende-se que a busca do capital por sua valorização está na base dos fenômenos de transferência de valor, desenvolvimento desigual e exportação de capital. Conforme esse processo de valorização se vê limitado, o capital procura maneiras de superar essas limitações. A própria tendência à queda na taxa de lucro aparece como motor da expansão do capital para a esfera internacional. Essa expansão gera, por sua vez, tanto efeitos em seus locais de origem quanto de destino, uma vez que generaliza as relações capitalistas de produção e torna a acumulação de capital e a dinâmica de concorrência, intrínseca a ele, processos globais. Nesse sentido, a atuação do capital na esfera global pode tanto reforçar o papel de determinados países na economia internacional, quanto revolucionar sua posição. Os processos de convergência e divergência, como tratados anteriormente, assumem também um caráter global. Conforme se aprofunda a internacionalização do capital, esses efeitos são dinamizados tanto nos países que tradicionalmente tiveram um acelerado desenvolvimento de suas forças produtivas, quanto naqueles em que historicamente demonstraram atraso.

O entendimento dado pelas teorias que buscam explicar o desenvolvimento desigual como resultado de uma polarização entre nações, num processo no qual a mais-valia gerada nas regiões atrasadas alimentaria o desenvolvimento econômico das avançadas, se confronta com essa realidade. Mesmo as transferências de valor ganham um novo contorno, dentro da abordagem aqui proposta. Como visto, assumem distintas direções, dependendo da estrutura dos capitais que atuam internamente em cada região. Dessa forma, as transferências líquidas de valor podem ser muito baixas ou até nulas, mesmo em países que detêm vantagens absolutas em setores de baixa composição orgânica. Dada as questões que se levantam sobre a dificuldade de se estabelecer uma relação direta entre transferência de valor e subdesenvolvimento, apontou-se a necessidade de abordar o desenvolvimento desigual como intrínseco à acumulação de capital. Entende-se, assim, que o processo concorrencial faz com que empresas e setores apresentem dinâmicas distintas de desenvolvimento, o que gera desigualdades no desenvolvimento eco- 
nômico das regiões onde esses capitais se localizam. Ao mesmo tempo, as características de cada local irão oferecer diferentes vantagens aos capitais que atuam em diferentes setores. Esses dois processos devem, assim, ser tratados conjuntamente de forma a se restabelecer a centralidade do capital e da relação capital-trabalho como objeto de análise na compreensão do desenvolvimento desigual.

\section{Referências}

AMIN, S. O desenvolvimento desigual: ensaio sobre as formações sociais do capitalismo periférico. Rio de Janeiro: Forense Universitária, 1976.

. The law of worldwide value. New York: Montly Review Press, 2010.

ASTARITA, R. Valor, mercado mundial y globalización. Buenos Aires: Ediciones Cooperativas, 2004.

BASKOY, T. Karl Marx's theory of market competition. Problématique: Journal of Political Studies, Toronto, v. 8, n. 1, p. 4-23, 2002.

BREWER, A. Marxist theories of imperialism: a critical survey. 2. ed. London: Routledge, 1990.

CARCHEDI, G. Frontiers of political economy. New York: Verso, 1991.

EMMANUEL, A. A troca desigual. Lisboa: Estampa, 1976. v. 1-2.

FRANK, A. G. Latin America: underdevelopment or revolution. New York: Modern Reader, 1970.

GUERRERO, D. Competitividad: teoría y política. Barcelona: Ariel, 1995.

La técnica, los costos, la ventaja absoluta y la competitividad. Comercio Exterior, México, v. 46, n. 5, p. 400-407, mayo 1996.

HOWARD, M. C.; KING, J. E. Unequal exchange. In: London: Macmillan Education, 1992. . A history of Marxian economics.

MALDONADO FILHO, E. A. A dinâmica da concorrência em Marx. Porto Alegre, 1990. Disponível em: <http://www.academia.edu/5298829/A_DINAMICA_DA_ CONCORRENCIA_EM_MARX >. Acesso em: 15 out. 2013.

MARINI, R. M. Dialética da dependência. 1973. Disponível em: < http://www.marxists.org/ portugues/marini/1973/mes/dialetica.htm>. Acesso em: 12 jan. 2014.

MARX, K. Grundrisse: foundations of the critique of political economy. New York: Vintage Books, 1973.

. O capital. São Paulo: Nova Cultural, 1986. (Os Economistas). Livro Primeiro Tomo II.

. O capital: crítica da economia política. São Paulo: Abril Cultural, 1984. (Os Economistas). Vol. II. Livro Segundo. 
PALMA, J. G. Why did the Latin America critical tradition in the social sciences become practically extinct? In: BLYTH, M. (Ed.). Routledge handbook of international political economy: IPE as a global conversation. Routledge: Mark Blyth, 2009.

SEMMLER, W. Competition, monopoly, and differential profit rates: A reconsideration of the Classical and Marxian theories. Revista Internazionale di Scienze Economiche e Commerciali, Milano, v. 29, n. 8, p. 737-762, ago. 1982.

SHAIKH, A. M. Competition and exchange rates: theory and empirical evidence. New York: New School for Social Research, 1991a. (Texto para discussão, n. 25).

Foreign trade and the law of value. Science and Society, v. 44, n. 1, p. 27-57, 1980a.

. Notes on the Marxian notion of competition. New York: New School for Social Research, 1979.

. The laws of international exchange. In: NELL, E. (Ed.). Growth, profits and property: essays in the revival of political economy. Cambridge: Cambridge University Press, 1980b.

. Valor, acumulación y crisis. Bogotá: Tercer Mundo Editores, 1991b.

WEEKS, J. The expansion of capital and uneven development on a world scale. London: SOAS, 1999. (Texto para discussão, n. 999).

Recebido em: 14/06/2016. Aceito em: 04/12/2016. 